\section{BIOPOLÍTICA, BIOECONOMIA, SUBJETIVIDADE: UMA ANÁLISE DAS PRINCIPAIS TRANSFORMAÇÕES LABORAIS NO CAPITALISMO CONTEMPORÂNEO}

\author{
Biopolitics, Bioeconomy, Subjectivity: An Analysis of \\ Significant Labor Changes in Contemporary Capitalism
}

\section{Biopolítica, Bioeconomia, Subjetividad: Un Analisis de las Principales Transformaciones Laborales en el Capitalismo Contemporaneo}

\author{
Biopolitique, Bioéconomie, Subjectivité: Une Analyse des \\ Principaux Transformations Laborieuses du Capitalisme \\ Contemporain
}

Biopolítica e Subjetividades
Contemporâneas

\title{
Resumo
}

Este trabalho tem por objetivo discutir, a partir do pensamento de Michel Foucault, a emergência da economia política como saber imanente à biopolítica e, a partir disso, situar a pertinência da noção de bioeconomia para pensar as atuais formas de regulação e governo das populações no contexto político do neoliberalismo, de modo a evidenciar as principais transformações ocorridas no mundo laboral a partir das atuais configurações do capitalismo contemporâneo. Para este fim, o trabalho foi organizado mediante a seguinte estruturação: a) salientou-se a pertinência da análise e da utilização da categoria da bioeconomia, partindo da construção da categoria da biopolítica em Foucault e da emergência da realidade da esfera econômica; b) destacou-se a posição da bioeconomia na análise do mundo do trabalho contemporâneo; e, mediante a relevância da categoria à análise dos pressupostos do novo mundo do trabalho, c) especificou-se as transformações ocorridas em relação à temporalidade sob o conceito da bioeconomia. Conforme o resgate da categoria a partir do próprio Foucault e do ensaio de reconstrução com autores contemporâneos, perceber-se-á que o conceito se mostra relevante para um entendimento mais específico das transformações do mundo do trabalho no século XXI, na medida em que estas sinalizam para uma captura das dimensões subjetivas implicadas na atividade laboral.

Palavras-chave: bioeconomia; biopolítica; Foucault; trabalho.

\section{Abstract}

This work aims to discuss, from the thought of Michel Foucault, the emergence of political economy as immanent knowledge to the biopolitics and, from that, to situate the relevance of the bioeconomy notion to think about the current forms of regulation and populations government in political context of neoliberalism, in order to highlight the main changes occurred in the labor world from the current settings of contemporary capitalism. To this end, the work was organized by the following structure: a) the relevance of the analysis and use of bioeconomy category was pointed, starting from the construction of biopolitics category in Foucault and from the emergence of the reality of the economic sphere; b) the bioeconomy position in the analysis of the contemporary labor world by the relevance of the category for the analysis of the conditions of the new world of work was highlighted; c) the changes occurred in relation to temporality, under the bioeconomy concept were specified. As the rescue of the category from Foucault himself and the reconstruction test with contemporary

Pablo Severiano Benevides ${ }^{(1)}$ Tainã Alcantara de Carvalho(2)

1) Professor do Curso de Psicologia (UFC/Sobral) e do Programa de PósGraduação em Psicologia (UFC/Fortaleza). Pesquisador do Laboratório em Psicologia, Subjetividade e Sociedade (LAPSUS UFC), do Núcleo de Estudos em Filosofia e Infância (NEFI - UERJ), do Grupo de Estudos Foucaultianos (GEF - UECE/ UFC) e Coordenador do diferenSa - grupo foucaultiano.

2) Bacharel em Ciências Econômicas pela Universidade Federal do Ceará e Mestrando do Programa de PósGraduação em Psicologia da Universidade Federal do Ceará. Colaborador do Viès Núcleo de Economia Política e membro do Núcleo de Psicologia do Trabalho-NUTRA.
Recebido em: 05/08/2015

Revisado em: 10/10/2015 Aceito em: 24/11/2015 
authors, it will be noticed that the concept shows itself relevant to a more specific understanding of the labor world changes in the twenty-first century, to the extent that these signal for capturing the subjective dimensions involved in labor activity.

Keywords: bioeconomy; biopolitics; Foucault; work.

\section{Resumen}

Este trabajo tiene como objetivo discutir, por medio de Michel Foucault, la emergencia de la economía politica como saber inmanente a la biopolitica $y$, de ahí, ubicar la pertinencia de la noción de bioeconomia para pensar las actuales formas de normativa y gobierno de las populaciones en el contexto político del neoliberalismo, de manera a evidenciar las principales transformaciones ocurridas en el mundo laboral partiendo de las actuales configuraciones del capitalismo contemporáneo. Con esta finalidad, el trabajo fue estructurado de la siguiente manera: a) Se resaltó la pertinencia del análisis y de la utilización de la categoría de la biopolitica en Foucault y de la emergencia de la realidad de la esfera económica; b) se evidenció el puesto de la bioeconomia en el análisis del mundo laboral contemporáneo, mediante la relevancia de la categoría para el análisis de los presupuestos del nuevo mundo laboral; c) se especificaron las transformaciones ocurridas en relación a la temporalidad, bajo el concepto de la bioeconomia. Según el rescate de la categoría por el propio Foucault y del ensayo de reconstrucción con autores contemporáneos, se percibirá que el concepto se muestra relevante para un entendimiento más especifico de las transformaciones del mundo laboral en el siglo XI, al paso que estas señalizan para una captura de las dimensiones subjetivas implicadas en la actividad laboral.

Palabras clave: bioeconomia; biopolítica; foucault; trabajo.

\section{Résumé}

Cet article a le but de discuter, à partir de la pensée de Michel Foucault, l'urgence de l'économie politique comme savoir immanent à la biopolitique et, à partir de cela, situer la pertinence de la notion de bioéconomie pour penser les actuelles manières de régularisation et gouvernement des populations dans le contexte politique du néolibéralisme pour évidencier les transformations qui sont arrivées au monde laborieux depuis les configurations actuelles du capitalisme contemporain. À cet effet, cet article a été organisé d'après la structure suivante: a) on a mis en relief la pertinance de l'analyse et de l'utilisation de la catégorie bioéconomie, à partir de la construction de la catégorie de biopolitique selon Foucault et de l'urgence de la réalité de la sphère économique ; b) on a détaché la position de la bioéconomie dans l'analyse du travail du monde contemporain, d'après la pertinance de la catégorie pour l'analyse des présuppositions du nouveau monde du travail ; c) on a spécifié les transformations qui ont eu lieu relationées à la temporalité sous le concept de bioéconomie. Selon le repérage de la catégorie à partir de Foucault et de l'essay de reconstruction avec des auteurs contemporains on remarquera que le concept se montre important à un apprentissage plus spécifique des transformations du monde du travail au XXIe siècle, en ce qu'elles indiquent la saisie des dimensions subjectives impliquées à l'activité laborieuse.

Mots-clés: bioéconomie; biopolitique; Foucault; travail.

\section{A Biopolítica e a Bioeconomia: Sobre a Emergência da Realidade Econômica e Biológica}

No primeiro volume de sua História da Sexualidade A Vontade de Saber, Foucault (2009) utiliza pela primeira vez em seus escritos o termo "biopolítica", expressão mencionada em palestra ministrada na PUC/RJ em 1974 e que, após a publicação da supracitada obra em 1976, constituiu-se como noção aglutinadora de uma série de reflexões sobre o governo das populações, tal como efetuado nos cursos "Em Defesa da Sociedade" (1976), "Segurança, Território, População" (1978) e "Nascimento da Biopolítica" (1979). Em linhas gerais, pode-se definir a biopolítica como a codificação de um conjunto de problemas e/ou acontecimentos relacionados à vida e à espécie humana a partir de uma racionalidade governamental que possui a população como alvo, os dispositivos de segurança como instrumento e a otimização da vida como fim.

Para que a segurança da população com vistas à otimização da vida possa efetuar-se, Foucault (2009) argumenta que foi necessária a autonomização de um tipo de realidade e de um tipo de saber. Trata-se, pois, do aparecimento da população em sua especificidade e da constituição de um saber próprio ao governo da população, também em sua especificidade - no caso, a economia política.

O que eu queria lhes mostrar era [...] o movimento que faz a população aparecer como um dado, como um campo de intervenção, como uma finalidade das técnicas de governo, [enfim] o movimento que isola a economia como domínio específico de realidade e a economia política ao mesmo tempo como ciência e como técnica de intervenção do governo nesse campo de realidade. (Foucault, 2009, p. 143)

Nessa ocasião, procura-se esclarecer justamente o vínculo entre o que Foucault (2009) evidenciou como a autonomização da economia como um "domínio específico de realidade" e os processos de captura da vida biológica na integração de uma racionalidade própria ao capitalismo contemporâneo. Em suma, trata-se de argumentar pela pertinência de uma noção como a de bioeconomia e, mais 
ainda, de argumentar pela importância da bioeconomia nas formas de reconfiguração, redefinição e recodificação da vida mediante as novas tendências do capitalismo. Começase, então, pelo primeiro ponto.

Nos cursos "Segurança, Território, População" (Foucault, 2009) e "Nascimento da Biopolítica" (Foucault, 2008), permanece constante a ênfase na transição de um tipo de poder caracterizado como poder soberano (ou, simplesmente, como soberania) para outra forma de poder ora caracterizado como biopolítica, ora como dispositivos de segurança, ora simplesmente como governo. Abstraindo a diferença entre esses termos, o que está em jogo é a substituição de um poder cujo objetivo é manter suas conquistas, assegurar um estado de obediência por parte daqueles a quem se dirige e maximizar os efeitos do poder no próprio exercício do poder - deslocamento de tudo isso para outra forma de praticar o poder.

Esse outro modo, ao contrário, não será exercido por imposição, não terá a obediência como finalidade e, indo um pouco além, somente poderá ser exercido mediante cautelosas e constantes preocupações com seus excessos. É nesse contexto que Foucault estabelece o registro próprio de ação dos dispositivos de segurança (o governo), diferenciando-os do registro da soberania (a lei) e da disciplina (a prescrição):

A lei proíbe, a disciplina prescreve e a segurança, sem proibir nem prescrever, mas dando-se evidentemente alguns instrumentos de proibição e de prescrição, a segurança tem essencialmente por função responder a uma realidade de maneira que essa resposta anule essa realidade a que ela corresponde - anule, ou limite, ou freie, ou regule. (Foucault, 2008, p. 61)

Ora, o que significa essa ação, por parte dos dispositivos de segurança, de "responder a uma realidade"? A partir da própria citação de Foucault (2009), já se tem uma pista: responder não significa proibir nem prescrever. No curso "Nascimento da Biopolítica" (2008), Foucault sublinha com mais ênfase que as ações do dispositivo de segurança são imanentes à racionalidade econômica própria ao neoliberalismo. Dessa forma, para responder à realidade é necessário, primeiramente, reconhecer, perceber, discernir o que é próprio à realidade. É necessário, ainda, que essa resposta de alguma forma seja extraída a partir de elementos da própria realidade - e não de uma lei, uma norma, um ideal, uma utopia que estaria acima da realidade ou lhe fosse, em alguma medida, transcendente. Por fim, é necessário que a resposta constitua, ainda, uma forma de respeitar essa realidade - quer dizer, que a resposta não queira impor de cima a baixo regularidades estranhas ou avessas a essa realidade, não "force a barra", não induza a uma resposta da resposta, e aceite a realidade para ser aceita por esta.
O conjunto dessas assunções, que politicamente estão acopladas, segundo Foucault (2009), à racionalidade governamental própria ao neoliberalismo, implicará na assunção de que há certa naturalidade nas práticas de governo. Isso significa que o governo, para bem governar, deve governar respeitando a natureza da população, suas regularidades, suas tendências, as características próprias de seu funcionamento - e, em última instância, a própria vontade da população. Fazendo referência a François Quesnay, Foucault (2009) bem percebe o modo como a relação entre desejo e governo é colocada sob a perspectiva dos fisiocratas e sua defesa de um sistema econômico livre e de caráter hedonista, e como essa própria perspectiva sinaliza o aparecimento das problemáticas relativas à população em sua positividade: "o desejo é aquilo por que todos os indivíduos vão agir. Desejo contra o qual não se pode fazer nada" (Foucault, 2008, p. 95).

Entretanto, não é porque nada se possa fazer contra o desejo que nada se pode fazer com o desejo. É aqui, justamente neste ponto, que desaparece a dicotomia própria a toda a filosofia política contratualista centrada numa compreensão do poder sob o signo da soberania: a dicotomia entre vontade (ou desejo) e governo (ou poder). É preciso, nesse contexto, contexto político próprio ao neoliberalismo e à biopolítica, sublinhar a existência, em relação ao desejo, de uma "naturalidade penetrável da população" (Foucault, 2008, p. 94). Como, então, governar a população sem governar contra a população?

É necessário agir sobre uma série de fatores, de elementos que estão aparentemente longe da própria população, do seu comportamento imediato, longe de sua fecundidade, da sua vontade de reprodução [...] é por todos esses fatores distantes, pelo jogo desses fatores que vai efetivamente ser possível agir sobre a população [...] não se trata de obter a obediência dos súditos em relação à vontade do soberano, mas de atuar sobre coisas aparentemente distantes da população, mas que se sabe, por cálculo, análise e reflexão, que podem efetivamente atuar sobre a população. (Foucault, 2009, p. 94)

Aparece, aqui, a noção de meio. O governo que bem governa a população não governa diretamente a conduta dos homens, não lhes impõe o que fazer, não busca inculcar uma ideologia ou mesmo a agir na produção de estados de coerção. O governo que bem governa a população deve governar num registro de realidade que não é exatamente o humano, ou o pessoal, ou o subjetivo - ele deve, indiretamente, atingir coisas que, por sua vez, atinjam o humano, o pessoal e o subjetivo. Portanto, o governo governa um meio e governa em um meio, na medida em que este se define como "o que é necessário para explicar a ação à distância de um corpo sobre outro [...], o suporte e o elemento de circulação de uma ação" (Foucault, 2009, 
p. 28).

Crê-se que se há elementos para argumentar sobre o fato de que há uma significativa correlação, expressa no pensamento foucaultiano, entre a emergência de uma realidade econômica e o governo das populações em sua materialidade biológica - o que torna adequado o uso da expressão "bioeconomia" no âmbito dos estudos foucaultianos. É preciso, entretanto, caminhar um pouco mais e sinalizar o caráter significativamente maleável, flexível e transformável que resulta do agenciamento entre esse campo de realidade e esse campo de saber. É preciso, ainda, situar as principais coordenadas que posicionam as estratégias de um governo subsidiado por uma bioeconomia - ou, se quiser, de um biogoverno - no contexto do capitalismo contemporâneo e das formas laborais que, sendo-lhes correspondentes, fornece-lhes o corpo concreto de suas transformações.

\section{Bioeconomia e Biogoverno no Capitalismo Contemporâneo}

Retorna-se à questão inicialmente posta, porém, não devidamente aprofundada: o que significa a naturalidade da população e em que consiste o seu caráter penetrável? Não haveria uma contradição entre aquilo que é natural e aquilo que é governável? Se uma população só age movida pelo desejo e se o governo nada pode contra o desejo, como o governo governa o desejo sem governar contra o desejo? É justamente essa redefinição nas relações que caracteriza o que Foucault (2008) chamou de homo oeconomicus. Seu aparecimento marca uma espécie de reversão no que tange às relações entre governo e subjetividade - pois, se no contexto do liberalismo, era necessário governar porque era necessário isolar um espaço neutro para a livre manifestação das características e potencialidades de cada um (de modo que a desigualdade social seria justificada como um reflexo das diferenças individuais), no contexto do neoliberalismo, desaparece a utopia desse espaço neutro. A desigualdade é primeira, fundamental e não poderá ser neutralizada para que emirjam as potencialidades de cada um.

A emergência do homo oeconomicus marca dois importantes deslocamentos no campo do governo e no campo do saber: não mais aquela instância subjetiva refratária ao governo, mas sim o homem "eminentemente governável" (Foucault, 2008, p. 369); não mais o ponto de desconhecimento perante um mundo cognoscível, mas o único reflexo de racionalidade perante um mundo caótico. O homo oeconomicus é o homem governável porque é o homem cognoscível, e é o homem cognoscível porque é o homem governável. Ele marca a superposição da economia política ao mesmo tempo como campo de saber e como campo de intervenção: "o homo oeconomicus é a única ilha de racionalidade possível no interior de um processo econômico cujo caráter incontrolável não contesta, mas funda a racionalidade do comportamento atomístico do homo oeconomicus" (Foucault, 2008, p. 383).

Isso implica, pois, em uma redefinição do registro de realidade em que atua a economia, no sentido de aproximála, de forma espantosa, com o registro de análise pertinente às psicologias que são norteadas pelo behaviorismo radical de Skinner. Isso é bem esclarecido por Foucault (2008), nas circunstâncias em que analisa o modo como os economistas da Escola de Chicago, em especial Schultz e Becker, situam o objeto da Economia.

Toda conduta que aceite a realidade deve poder resultar em uma análise econômica. O homo oeconomicus é aquele que aceita a realidade. A conduta racional é toda conduta sensível a modificações nas variáveis do meio e que responde a elas de forma não aleatória, de forma, portanto sistemática, e a economia poderá, portanto, se definir como a ciência da sistematicidade das respostas às variáveis do ambiente. (Foucault, 2008, p. 368)

Assim, a economia política obtém seu corpo concreto a partir de um conjunto de técnicas no qual o que está em jogo é compreender e, ao mesmo tempo, transformar a sistematicidade das respostas às variáveis do ambiente. Para transformar as respostas, não de modo transitório, esporádico ou circunstancial - tal como uma ordenação ou uma inculcação-, mas sim de modo sistemático, é necessário gerar um efeito de subjetivação nas práticas de governo. Será esse efeito de subjetivação nas práticas de governo que garantirá certa segurança (em termos de sistematicidade de respostas) sem que essa dependa de um controle externo, coercitivo ou heteronômico. É justamente nesse sentido e com esses objetivos que aparece a necessidade de uma substituição do controle pelo autocontrole (Boltanski \& Chiapello, 2009), correlata às formas de regulação horizontais pelas verticais (Deleuze, 2010), bem como uma perspectiva que não mais situará em oposição o controle e o autocontrole, mas que situará como objeto privilegiado do controle produzir sujeitos que se autocontrolem.

Em O Novo Espírito do Capitalismo, os sociólogos franceses Luc Boltanski e Ève Chiapello (2009) situam o momento de transição do segundo espírito do capitalismo para o terceiro espírito do capitalismo - que é por eles chamado justamente de "novo espírito do capitalismo" - na substituição das reivindicações quantitativas e das reivindicações por garantias de trabalho pelas reivindicações qualitativas e centradas, fundamentalmente, na obtenção de autonomia. Trata-se, pois, de uma resposta dada às insatisfações do mundo laboral, que foram traduzidas por uma parcela progressista do patronato (Boltanski \& Chiapello, 2009) como reivindicações por maior liberdade, autorrealização, criatividade e autenticidade no mundo do trabalho. Em suma: por reivindicações que, não 
reivindicando diretamente a autonomia, obtiveram, sob o nome de "autonomia", uma série de transformações na dinâmica laboral.

As medidas que tinham em vista dar maiores garantias aos assalariados foram substituídas por medidas que visavam a tornar mais leve o controle hierárquico e a levar em consideração os "potenciais" individuais. Por uma inversão política, as garantias foram de algum modo trocadas pela autonomia. [...] Será no plano das condições de trabalho que essa nova política se afirmará. A atenção dada à melhoria das condições de trabalho, ao "enriquecimento das tarefas" ou aos "horários flexíveis" terá o efeito, por um lado, de ganhar adesão de uma parte dos assalariados, ao apresentar vantagens personalizadas que as ações coletivas não podiam oferecer, e, por outro, de devolver a iniciativa ao patronato, ao individualizar as condições de trabalho e as retribuições. (Boltanski \& Chiapello, 2009, p. 225)

Sob uma gramática geral da autonomia e da realização pessoal, encontra-se, ainda, um conjunto de reivindicações fundamentais para a configuração do novo espírito do capitalismo - reivindicações que Boltanski e Chiapello (2009) consideraram como gravitando em torno da noção de autenticidade. Novamente, parte significativa das transformações do capitalismo teria a ver com o modo como essas reivindicações foram interpretadas e encaminhadas. Isso permitirá compreender as roupagens com que são revestidas a introdução do elemento subjetivo no processo laboral - o que, a partir da perspectiva foucaultiana, não constitui uma exceção de bom grado nem uma peça adjacente nas práticas de governo efetivadas sob o solo político do neoliberalismo e sob os fins de uma biopolítica. Trata-se, fundamentalmente, de um conjunto de demandas que, explorando o elemento subjetivo como diferencial de autenticidade na prestação de serviços que exigem cada vez mais uma doação integral ao trabalho e um tipo de produção singularizada, intitulam a si mesmas de demandas por humanização do trabalho (Boltanski \& Chiapello, 2009).

Essas demandas por humanização, todavia, fazem o tiro sair pela culatra: ao reivindicar serviços e trabalhos mais humanos, relações mais informais e pessoais, bem como uma proximidade maior entre os funcionários e a empresa, findam por acelerar a "mercantilização de bens que até então tinham ficado fora da esfera do mercado" (Boltanski \& Chiapello, 2009, p. 444). É exatamente a introdução do elemento qualificado como humano naquilo que conta e aparece como trabalho - o que constitui geralmente uma exigência das reivindicações por autenticidade - que instaura uma incerteza quanto à autenticidade dos próprios seres humanos nestas relações. Pois, se o que era antes qualificado como humano consistia precisamente naquilo que não poderia ser incorporado às funções laborais, eis que agora essa incorporação trará uma série de incertezas e dissolverá muitas fronteiras que outrora separavam de forma nítida os aspectos formais de um trabalho daqueles propriamente humanos.

Os elementos pessoais que intervém na transação, sem entrarem diretamente na definição do serviço vendido, podem estar presentes de maneira espontânea, não premeditada ou, ao contrário, ser resultado de seleção ou de formação específica, de tal modo que fica sempre suspensa e frequentemente sem resposta a questão da verdadeira natureza da relação (puramente "comercial" ou também associada a sentimentos "reais"). [...] A importância atribuída ao papel de mediador, às relações pessoais, à amizade e à confiança na realização do lucro num mundo conexionista e, correlativamente, o enfraquecimento da distinção entre vida privada e vida dos negócios tendem assim a introduzir na esfera comercial relações que antes se definiam precisamente como "desinteressadas". (Boltanski \& Chiapello, 2009, p. 445)

Essa incerteza faz com que as próprias relações pessoais adentrem o reino das inseguranças, uma vez que se encontram sob suspeita precisamente as referências daquilo que caracterizam, por exemplo, uma verdadeira amizade, uma manifestação de sentimento espontânea, um afeto desinteressado, uma afeição gratuita ou uma afinidade fortuita. Assim, a mercantilização da diferença, da singularidade e dos elementos qualificados como "humanos" - entendidos aqui como a intervenção implícita e ininterrupta das características humanas nas transações comerciais e nas seleções e avaliações constantes no âmbito do trabalho - atingem um efeito bastante paradoxal. Se as reivindicações por autenticidade visavam à introdução do que é humano da dimensão no trabalho, sua consequência foi justamente a instalação de uma suspeita generalizada quanto àquilo que é autenticamente humano nas relações pessoais.

Há, pois, um jogo um tanto anacrônico que obriga à perpétua frustração qualquer reivindicação por autenticidade no interior da lógica capitalista. Isso ocorre porque "os bens chamados de 'naturais' ou 'autênticos' [...] precisam apresentar-se com aspectos que façam referência a um estado anterior das relações comerciais" (Boltanski \& Chiapello, 2009, p. 449). Ora, mas como encontrar essa relação natural, autêntica ou espontânea do criador com sua obra se ela é encontrada precisamente em contextos de comercialização? Assim, o ponto em que Boltanski e Chiapello (2009) insistem é que essas reivindicações instalam uma série de inquietudes, incertezas e suspeitas que consistirão na própria mola propulsora desse processo de mercantilização do autêntico: "a mercantilização provoca, assim, novas formas de inquietação sobre a autenticidade 
das coisas ou das pessoas, por não se saber se elas são 'autênticas' ou 'inautênticas', espontâneas ou configuradas para fins comerciais” (Boltanski \& Chiapello, 2009, p. 450).

Uma vez evidenciada a pertinência do conceito de bioeconomia a partir de uma compreensão de que a emergência de uma economia política como ciência de governo deveu-se à emergência das problemáticas relativas ao governo da população como governo do meio, do ambiente e da natureza imanente a esta população; e, ainda, uma vez situadas algumas das principais coordenadas mediante as quais as relações entre governo e subjetividade são agenciadas, sob uma forma que se poderia chamar de biogoverno, no contexto do capitalismo contemporâneo, acompanha-se agora o percurso deste trabalho rumo a análises mais específicas no campo laboral. Estas análises pretendem mostrar o tratamento que tem sido dado à categoria da bioeconomia, bem como a especificação do tipo de controle exercido na contemporaneidade, tal como se mostra no controle sobre o tempo de trabalho, controle esse que é incessantemente ressignificado pelas práticas de regulação próprias do capitalismo atual como autocontrole.

\section{Neoliberalismo e Bioeconomia: Do Controle Biológico ao Controle Subjetivo no Mundo do Trabalho}

$\mathrm{Na}$ perspectiva da contemporaneidade, o conceito de bioeconomia em muito dialoga com as transformações do sistema de produção capitalista, mais especificamente sob a "agenda" neoliberal, sendo, neste caso, mais explícita. Em uma maior amplitude do sistema produtor de mercadorias - um sistema criador de necessidades e formador de novos valores e comportamentos -, o debate sobre a bioeconomia ganha maiores horizontes, principalmente ao lhe ser incluído o caráter cognitivo do capitalismo contemporâneo.

Enfatizada, dentre outros fatores, pela privatização acelerada, pelo enxugamento do Estado e pelas políticas fiscais e monetárias sintonizadas com os organismos mundiais de hegemonia do capital (Antunes, 2000), a política neoliberal surge, em confronto ao modelo fordista/ taylorista em crise, como saída para a implementação de um novo modelo de produção: o modelo baseado na flexibilização e na subcontratação da força de trabalho. Com a exploração das peculiaridades de cada nação, com os baixos custos de matérias-primas e mão de obra e presença de incentivos fiscais, o trabalhador - tal como a produção - se mundializa. Isso implica, conforme destaca Antunes (1999), uma sujeição a um processo de des-territorialização e re-territorialização do sujeito e do trabalho, que se tornam flexíveis, adequada às variadas situações do mercado de trabalho e da economia global.

Consequências da estratégia para "ajuste" da economia perante a crise (Aquino, 2008), a flexibilização e a precarização abalam os laços contratuais presentes no antigo modelo de produção, abrindo espaço ao subproletariado. Estes são compreendidos pelos terceirizados, subcontratados, part-time (Antunes, 2005) e demais grupos desvinculados das formalidades contratuais de trabalho e dos direitos e garantias gozados pela classe trabalhadora.

A economia sob a égide neoliberal, assim, gera um indivíduo atormentado devido às constantes transformações e demandas do mundo do trabalho. As percepções acerca dos males provocados pela alienação do trabalho na contemporaneidade são variadas, dentre os quais se destacam a ressignificação do trabalho, percebido agora como um encargo e uma tortura (Codo, Sampaio, \& Hitomi, 1993), e os problemas psicossociais advindos de uma "dessubjetivação do trabalho", como o esfacelamento da noção de coletividade e da identificação entre os trabalhadores e a negação do sofrimento proveniente do trabalho alienado (Dejours, 1999). Isso se reflete nos laços sociais presentes fora do espaço laboral; e, ainda, a adoção de novas identidades, provenientes da falência do Estado de Bem-Estar Social e da imposição da concorrência a partir do espaço laboral (Bendassolli, 2000). Sobre este, Codo, Sampaio e Hitomi (1993) apontam que a adequação dos indivíduos à constante situação de concorrência se torna essencial à sobrevivência e à individualidade do ser, pois o pagamento do trabalho, o salário, é que aparece não só como meio de acesso à educação e cultura, por exemplo, mas, em si, como "fundamento da cidadania possível" (Codo, Sampaio, \& Hitomi, 1993, p. 163).

Nesse contexto, a crítica da sistematização política neoliberal, apesar de necessária, não parece inteiramente suficiente à compreensão das mudanças contemporâneas. O entendimento das consequências das "metaformoses" do trabalho nas últimas duas décadas (como é o caso do Brasil, onde se percebeu o avanço do ideal neoliberal a partir do início da década de 1990) deve adotar percepções dinâmicas no que se diz respeito à transformação da realidade, indo do amplo ao mais íntimo, do individual ao público. Assim, especifica-se, com esse viés mais voltado à transformação do trabalho assalariado para trabalho imaterial e à maior inserção da subjetividade e da percepção da realidade e sua dimensão espaço-temporal, a própria bioeconomia foucaultiana, já exposta anteriormente.

Mediante a complexidade percebida pela cooptação do capital sobre o trabalho, todavia, uma análise complementar e mais esclarecida sobre a bioeconomia pode ser desenvolvida, provendo o termo de uma significação mais clara e consoante aos paradigmas da contemporaneidade. Conforme apontado de maneira sucinta por Costa (2010, p. 25), pode-se entender a categoria, na contemporaneidade, como um conjunto de "estratégias específicas de uma economia que tem como objeto a vida e suas condutas de consumo, satisfação, prazer, gosto e saúde". Nesse sentido 
mais amplo, localiza-se, na fala de Chicchi (2010), a indicação da principal característica do trabalho sob a visão de uma bioeconomia:

A prática laboral de uma parte cada vez maior de pessoas de fato, hoje, já não tem mais a ver com a execução passiva e hétero-dirigida de operações, mas sim com o tratamento de informações e conhecimentos, com o investimento da própria subjetividade em relações de trabalho e/ou com o desenvolver inovações de produtos e de processo. Em outras palavras, a importância da atividade produtiva "rotineira" e do trabalho material, que consiste em transformar a matéria-prima através da ajuda de instrumentos e de máquinas, também materiais, diminui em favor de um novo paradigma do trabalho contemporâneo mais intelectual, imaterial e relacional. Para ser eficiente e apetecível, o trabalho deve hoje fazer-se de fato empreendedor, capaz de contribuir à solução (segundo as competências e em diferentes níveis de responsabilidade) dos problemas que uma atividade de empresa encontra em seu acidentado caminho competitivo. (Chicchi, 2010, para. 19-20)

Em resumo, conforme aponta o autor, a caracterização de bios concedida à economia indica o real caráter do sistema econômico capitalista contemporâneo: com a presença das informações em tempo real e o rápido processamento de dados objetivados à facilitação do processo produtivo, mais do que a desestabilização do mercado de trabalho, do rompimento de barreiras temporais e espaciais presente na atualidade, a bioeconomia faz referência ao controle exercido pelo mercado de trabalho sobre todas as instâncias da vida privada e da vida "pública". A esfera econômica - ou, mais especificamente a percepção de "capitalização" da realidade - passa a ser exposta e percebida como "única textura possível do Sentido e, paradoxalmente, como uma espécie de fundo antropológico originário" (Chicchi, 2010, para. 1).

Desse modo, à luz do possível deslocamento que aqui se ensaiou - a saber, da biopolítica para a bioeconomia -, podem ser percebidos, apenas como exemplos, dois pontos de reflexão sobre a perspectiva da esfera econômica e da própria história econômica que podem gerar, afinal, uma reflexão sobre o conteúdo do pensamento foucaultiano e da própria noção de bioeconomia, dotando-a de relevância à análise do sistema econômico contemporâneo. São eles: a) a visão sobre o Estado de Bem-Estar Social enquanto um primoroso dispositivo de segurança em si (Lazzarato, 2006); e b) a percepção das mudanças do funcionamento da bioeconomia, passando esta das mãos do Estado às mãos do livre mercado, gerando uma maior profundidade das ferramentas bioeconômicas de dominação da população, como é o caso do sistema político-econômico neoliberal.

Quanto ao primeiro, o caráter das políticas do Estado

de Bem-Estar Social, enquanto ferramentário consoante aos dispositivos de segurança foucaultianos, deve ser dado destaque à sua consonância para com as políticas das empresas. Servindo a favor da normalização dos indivíduos durante o pós-Segunda Guerra Mundial ao funcionamento do sistema de produção capitalista, desmascara-se o caráter assistencialista do governo: na verdade, a instituição busca, ao lado das empresas, a superposição do capital, debilitado pela quebra da bolsa de valores norte-americana:

Lutar pelo desenvolvimento e pela realização dos direitos econômicos, sociais e políticos, por muito meritório que seja, não é o mesmo que lutar pelo socialismo. E mais, a concessão e a aquisição desses direitos têm a intenção oposta. Seu objetivo é integrar as forças e as classes dominadas ao sistema. Como escreve Burawoy, outro autor influenciado pela Escola de Frankfurt, "a própria possibilidade de ampliar os direitos pessoais permite ao capitalismo lograr consenso entre os pobres e os oprimidos. (Navarro, 1993, p. 158)

Nesse sentido, faz-se necessário pensar, por exemplo, durante o período considerado, a criação e a expansão de um modo de vida norte-americano, a formatação da célula da população, a família, conforme as necessidades de expansão do poder do capital, de uma cultura moral e de consumo características. Importante ressaltar que, de acordo com Navarro (1993), o próprio Ford identifica, nas políticas de intervenção do Estado e em suas medidas assistencialistas, uma saída para a crise, atuando ele mesmo em prol da classe trabalhadora por meio do aumento de salários. Não apenas se desmascara o caráter do Estado, mas também os verdadeiros interesses por trás dos auxílios financeiros, tentando inserir, sob a égide técnica dos dispositivos de segurança, a população sob um estado constante de dominação e aceitação consensual às normas econômicas, à intensificação do poder de polícia e à maximização de um poder que se apoia numa gestão calculista do medo. Navarro (1993) deixa este aspecto muito claro:

Dessa forma, o Estado de Bem-Estar - um triunfo da classe trabalhadora, conquistado com um custo enorme de sangue, suor e lágrimas - é considerado uma reforma legitimizadora, outorgada pela classe capitalista com o efeito de criar uma aceitação consensual de seu papel. Para o pensamento fordista, o Estado de Bem-Estar é um passo histórico astuto dado pela classe capitalista, que não só legitima o papel do capital, como além do mais assegura o consumo da produção em massa introduzida por Henry Ford. (Navarro, 1993, p. 161)

Com relação ao segundo aspecto - a saber: a passagem do vetor bioeconômico, enquanto ferramenta, do Estado para o mercado -, o próprio entendimento sobre o conceito 
se torna tanto mais caracterizável quanto perceptível sob a economia neoliberal. O sistema produtor de mercadorias neoliberal demonstra como principal característica a determinação da economia, em si, como bioeconomia, uma ferramenta de controle e manutenção do poder pelo ferramentário econômico. Mais do que a exploração voltada ao esforço físico e à exploração evidenciada pela determinação entre os tempos de trabalho e de lazer - ou não-trabalho -, como foi caraterizado o período industrial, o capital passa a cooptar o indivíduo por meio de seu aparelho psíquico, fator pelo qual a bioeconomia se mostra associada aos processos de produção imaterial (Fumagalli, 2010b).

Nesse sentido, trata-se de um capitalismo manipulatório (Alves, 2011) ou cognitivo (Fumagalli, 2010b). Dentre os termos expressos, compreende-se que o sistema econômico pode ser entendido enquanto uma mescla de ambas as classificações: inicialmente como sistema de novos valores e comportamentos que se inserem enquanto fatores principais de construção de uma nova subjetividade, o mesmo passa a exercer um sentido de controle sobre o indivíduo. Isso ocorre ora em termos de mercado de trabalho - a partir do qual gera comportamentos de agressividade, formalmente inseridos em um sentido de "competição" plena e dita "justa" -, ora em relação à desfragmentação da vida "privada", dentro da qual se destaca o desgaste dos laços relacionais ("fetichizados" enquanto relações de cunho estritamente econômico) e o desgaste da família, na qual se torna difícil o prolongamento de narrativas sustentáveis (Sennett, 2011).

Destarte, com a caracterização da economia neoliberal enquanto período de mudanças das instituições de poder, resgata-se a análise de Foucault (2008, 2009) acerca da relação governo-população-economia política, na qual o Estado de governo atua mediante um conjunto de práticas articuladas sob a forma de um dispositivo de segurança (como forma de normação do meio à vontade do mercado) e de disciplina (sancionando e punindo com vistas à obtenção de uma normalização dos indivíduos). E ainda: na nova morfologia do funcionamento da sociedade, ao contrário do período em que a figura do soberano reinava, na contemporaneidade o exercício das formas de dominação tende ao anonimato. Como bem explica Fumagalli (2010a), ao comparar o modelo fordista e o novo modelo cognitivo da bioeconomia:

Nos últimos 30 anos, ela [a centralidade dos mercados financeiros] substituiu o Estado como assegurador social (canalização forçada de parte crescente dos rendimentos do trabalho - previdência, instrução, saúde). Deste ponto de vista, os mercados financeiros representam a privatização da reprodução da vida, uma vez ultrapassada a sociedade salarial. São, portanto, um biopoder. Ou melhor, enquanto biopoder, as finanças são um dos elementos do comando bioeconômico sobre as forças do trabalho vivo. A crise das finanças é, portanto, crise da governança financeira do biopoder atual. (Fumagalli, 2010a, pp. 11-12)

Visando à construção de uma base investigativa sobre a construção temporal a partir da relação do mercado de trabalho com a construção realizada até então sobre a bioeconomia, partir-se-á às mudanças ocorridas no estabelecimento do tempo de trabalho do sujeito, atualmente dinamitada pelo trabalho imaterial, que esfumaça a linha uma vez bem delimitada entre o tempo de trabalho e o tempo de ócio ou não-trabalho. Esse aspecto se revela, conforme se procurará demonstrar a seguir, enquanto ferramenta aplicada pelo capital de entrega do indivíduo à produção capitalista, desestabilizando os laços do trabalhador com os pares e ele, em seu espaço privado, com sua família.

\section{A Temporalidade e o Controle sobre o Trabalhador}

As transformações ocorridas dentro do mundo do trabalho são multivariadas e sua frequência é constante. Passados os anos de recrutamento de uma classe trabalhadora apenas fisicamente resistente frente aos trabalhos extenuantes, hoje o indivíduo se vê acuado diante do mercado de trabalho, que cada vez mais espera do sujeito não mais a capacidade de trabalhar, mas a colaboração junto à empresa, um enviesamento da relação de classes que torna uno o objetivo de grupos tão distintos, a saber, a expansão do capital. Isto envolve desde o know-how adquirido pelo indivíduo durante sua vida até a disposição em realmente "vestir a camisa" da empresa. Com isso, o processo de adequação do indivíduo às intempéries de um mercado competitivo começa cada vez mais cedo, sendo esta percepção da vida imbuída e incentivada desde a educação até o espaço familiar.

Adicionada ao acirramento das disputas dentro do mercado de trabalho, evidente se mostra a volatilidade do mercado de trabalho nos últimos anos, bem como suas novas imposições. Para efeito de exemplificação, são citados dois exemplos: o primeiro se baseia nas proposições realizadas pelas Medidas Provisórias 664 e 665 de 2015, bem como do Projeto de Lei 4.330/04 (aprovado apenas em 2015) no Brasil que desestabilizam os direitos do trabalhador e regulamentam uma situação de vulnerabilidade no trabalho, desejada pelas empresas para uma maior lucratividade e menores custos em garantias trabalhistas durante períodos de recessão. O segundo caso se baseia nos "contratos de zero horas" (Sahuquillo 2015), que, espalhando-se inicialmente pelo Reino Unido, determinam aos contratados (os denominados "ultraflexíveis") a ausência de uma garantia mínima de direitos ao sujeitar o tempo do indivíduo à exclusiva necessidade da empresa, deixando-o em uma situação de total dependência e sujeição. 
No cerne das transformações ocorridas no mundo do trabalho, conforme salientado anteriormente, destaca-se a temporalidade. Buscando situá-la neste estudo, pontua-se a contribuição marxiana, que tem o tempo enquanto núcleo da exploração do trabalhador pela produção industrial. Por meio dele, Marx (1980) estabelece a categoria de mais-valia, o tempo excedente de trabalho realizado pelo trabalhador ao buscar o pagamento da própria mão de obra - mas que não é pago -, enquanto força-motriz à manutenção e expansão do capital (e, no caso da mais-valia relativa, também a intensidade do trabalho, considerando com isso o avanço tecnológico dos meios que compõem o processo produtivo). Nesse sentido, o tempo de trabalho e o tempo de não-trabalho puderam ser mais facilmente delineados e separados, principalmente caso se resgatasse o caráter do trabalho, estafante, realizado e a desapropriação dos meios de produção da classe trabalhadora, o que a torna produtiva apenas no espaço de trabalho. Nesses aspectos, Imbrizi (2005) contribui com a discussão sobre o caráter destes distintos momentos da vida do indivíduo, a partir da seguinte perspectiva:

Essa distinção enraíza-se de forma que o segundo [o tempo livre] precisa contrapor-se ao primeiro e assim vinculase às atividades sem sentido e sem responsabilidade. A imbecilidade de muitas ocupações do tempo livre tem por objetivo não gastar energia $\mathrm{e}$, sim, preparar corpo e mente para a maior produtividade no ambiente de trabalho. O tempo livre transforma-se em apêndice do tempo de trabalho. (Imbrizi, 2005, p. 43)

O sentido aplicado ao "preparar corpo e mente para a maior produtividade no ambiente de trabalho" se esvanece em parte ao se situar no centro da discussão a fluidez do mercado e a imaterialidade do trabalho e da produção (Archela, 2012; Fumagalli, 2010b) na contemporaneidade. Incluem-se essas ressalvas por se entender que o tempo de lazer, exercido no não-trabalho, estabelece-se mais enquanto tempo de desenvolvimento pessoal e social dos indivíduos (Aquino \& Martins, 2007). O tempo de não-trabalho, com o avanço do capitalismo cognitivo, adquire uma nova conotação de tempo útil ao trabalho ou para o trabalho, como é o caso da busca constante pela profissionalização. Ademais, destaca-se que, enquanto momento em si de "lazer", essa parcela do tempo pessoal é percebida enquanto momento de igual captura da subjetividade, vide a cooptação realizada cotidianamente pela "Indústria Cultural", sobre a qual comerciais, propagandas e programas televisivos criam novas necessidades e valores, e a partir da qual o reforçamento de certas opiniões, comportamentos e valores é percebido por meio das relações sociais.

Sob este aspecto é que se pauta a bioeconomia foucaultiana, com sua funcionalidade adquirida pelo Estado de governo de ferramenta de sutil dominação sobre a população, enquanto estratégia pertencente não mais ao Estado, mas, agora, sob os aspectos desestabilizadores do mercado neoliberal que, especificamente, marcam o tempo e o trabalho, em sua relação dialógica, como núcleos de dominação do indivíduo e, de forma mais geral, da população. Trata-se, pois, do processo que Foucault (2008) chamou de governamentalização do Estado. Esse cenário se torna mais evidente ao se ressaltar, no contraste entre Estado de Bem-Estar Social e o cenário de Estado Mínimo, a percepção sobre o centro organizativo da sociedade. No primeiro caso, tem-se uma realidade mais estável, na qual a passibilidade de delimitação entre o tempo de trabalho e o tempo livre (e neste se pode passar a incluir os mais diversos aspectos, como relacional, familiar, de repouso, de ócio, de lazer, de manutenção da força de trabalho) abrem espaço ao arraigamento do indivíduo em uma realidade que lhe parece própria. Já no segundo caso, percebe-se o tempo enquanto "tempo econômico", produtivo, no qual o aproveitamento do tempo à produção de um sujeito econômico se sobrepõe, em termos gerais, ao tempo de vida do indivíduo na qualidade de ser social. Dessa forma, 므 tempo livre igualmente se torna um objeto bioeconômico), sendo utilizado à retroalimentação do capital, seja pela via econômica (tempo de efetivação das relações econômicas e de superespecialização do trabalho), seja pela via da desestruturação da coletividade - o que se faz presente, por exemplo, nos sindicatos e nos movimentos sociais, os quais, aparentemente improdutivos, são rechaçados em nome de uma utilização mais produtiva do tempo. Imbrizi (2005) explica que, sob a sistemática do capitalismo tardio, o tempo de lazer

[...] pode ser ocupado em uma corrida desesperada por cursos de especialização que supostamente garantiriam a manutenção do emprego ou aumentariam as possibilidades de consegui-lo. Pode ser ocupado com atividades esportivas nas quais a busca por um corpo perfeito, magro e saudável é precondição dos padrões de beleza que condicionam os critérios seletivos para todo e qualquer posto de trabalho e, assim, ao exercitarem desesperadamente os seus corpos, "as pessoas adestramse sem sabê-lo para as formas de comportamento mais ou menos sublimada que delas se espera no processo de trabalho". Pode ser ainda ocupado por pseudoatividades eou por meio do consumo dos produtos da Indústria Cultural. O tempo livre, assim usufruído, desemboca no tédio que "existe em função da vida sob a coação do trabalho e sob a rigorosa divisão do trabalho". (Imbrizi, 2005, p. 44)

Igualmente, o tempo de trabalho se torna fluido ao longo do tempo do ser social, encaixando-se nos interstícios do período considerado de não-trabalho. Nesse aspecto, necessário se torna invocar a atual percepção sobre a 
bioeconomia, a partir da qual se depara com uma acepção da subjetividade pela produção de mercadorias, sendo, para isso, situada a intensificação do trabalho imaterial enquanto nova faceta do trabalho na contemporaneidade.

Fumagalli (2010a, 2010b) demonstra que, sob a perspectiva do capitalismo cognitivo, o trabalho do século XXI se modificou em sua atividade, não sendo mais baseado na materialização de uma pré-concepção da necessidade. Inserido principalmente no terceiro setor econômico, o de serviços, o processo do trabalho imaterial, bem como o produto final, torna-se calcado, como destaca Lazzarato (2006, p. 88), sobre "as linguagens, os afetos, os saberes e a vida, articulados através do trabalho reprodutivo, que se tornam produtivos". Da mesma forma, enquanto produtores de conhecimento e informação, os trabalhadores sob a era da informação passam por uma cooptação psicológica no trabalho, sendo explorados da classe trabalhadora não apenas a resistência física e o tempo de trabalho contratualmente definido, mas a capacidade cognitiva no processo de produção, o alcance de metas pré-estabelecidas e, principalmente, a atualização constante de métodos, linguagens e dinâmicas de trabalho. Segundo Fumagalli (2010a):

As formas de comando do capital sobre o trabalho são formas de controle e de comando sobre as faculdades cognitivas dos seres humanos, e não apenas disciplinamento do corpo. A disciplina da fábrica, atuada através dos tempos pela máquina física, tende hoje a ser substituída por processos de controle social e cerebral, que impelem para formas de autocontrole e autorrepressão. Hoje, o biopoder é controle dos processos formativos e construções de imaginários que tendem a subsumir a vida dos indivíduos. (Fumagalli, 2010a, p. 12)

Dentro desses aspectos que caracterizam o mundo do trabalho na contemporaneidade, a desestruturação de um tempo de trabalho fixo, antes delineado em consonância à vontade do trabalhador, conforme percebido no modelo de produção fordista/taylorista, bem como a instabilidade percebida pela volatilidade do mercado de trabalho, geram consequências não apenas à saúde do indivíduo, ao ser flexibilizado e sujeito a uma heteronomia inclusive de seu próprio tempo de vida - no trabalho e na liberdade deste. Esses fatores agem igualmente sobre os laços de solidariedade percebidos dentro do espaço de trabalho, atingidos pelo discurso da competitividade e que acabam por levantar discursos de ódio pautados na raça e gênero dos pares.

Por fim, deve ser mencionada a própria desestruturação das representações sindicais enquanto últimos representantes de força dos ideais e garantias trabalhistas. Neste aspecto, Fumagalli (2010b) aponta que, mediante uma inserção do trabalho imaterial (e das atividades imediatamente correlacionada a ela, como a profissionalização e a especialização) na vida pessoal do indivíduo, conforme visto anteriormente, sendo este o melhor representante de sua própria posição no processo produtivo, a heterorrepresentação realizada pelo sindicato, que historicamente tem demonstrado maior força de embate contra a deturpação dos direitos dos trabalhadores, vem sendo substituída pela autorrepresentação, "pela representação da diferença e não das diferenças", produzindo "tensões centrífugas que podem se dilatar até causar a destruição da rede como forma de organização da representação" (Fumagalli, 2010b, p. 312, tradução livre).

Nesse sentido, explicita-se, então, a sutil perversidade presente no capitalismo cognitivo, conforme aponta Fumagalli (2010b). Importante salientar que é através do entendimento do sentido exposto pela análise da bioeconomia que o caráter manipulatório do sistema político neoliberal, em si, é agregado de sentido. Dialogando com a contemporaneidade, a pulverização da movimentação sindical, bem como sua corrosão por dentro, tanto no sentido de enfraquecimento da própria "organização", de seu nome, quanto em seu enfraquecimento pela quebra de identificação dos trabalhadores enquanto indivíduos que possuem em comum seu papel social na (re)produção político-econômica, demonstram ser os principais fatores de impacto sobre o desarraigamento e alienação dos trabalhadores. Assim, pelo controle gerado sobre o tempo de trabalho, desagregam-se os trabalhadores de seu principal instrumento de resistência, tornam-se, assim, facilmente manipuláveis e cooptados por meio de uma falsa liberdade. No âmbito da produção de uma nova representação da classe trabalhadora, Fumagalli (2010b, p. 324, tradução livre) afirma que, frente ao capitalismo cognitivo, um reaparecimento do poder sindical por meio de uma ação biosindical se mostra necessário "para a refundação de uma capacidade sindical de ação", a partir da qual, com um entendimento sobre realidade que ultrapasse a comum ortodoxia marxista sobre a divisão da sociedade e sobre a materialidade da exploração no processo produtivo, ou seja, que leve em conta a flexibilidade dos sujeitos, a comunicação em rede (além da própria necessidade em aderir a esta linguagem) e a horizontalização das hierarquias nas empresas, possa atingir e tornar visível a penetrante exploração do capitalismo cognitivo sobre o indivíduo.

\section{Reflexões Finais}

Este estudo, conforme explicitado em momentos anteriores, pretendeu explicitar a articulação entre a biopolítica e o advento da economia política - e, mediante isto, argumentar pela pertinência das noções de bioeconomia e biogoverno no interior da perspectiva foucaultiana com vistas à análise das atuais formas de controle e gestão da 
população. Seu objetivo, ainda, consistiu em compreender a pertinência dessas noções não a todo e qualquer contexto político ou a toda e qualquer perspectiva de análise política - diferentemente, procurou-se mostrar como essas noções são imanentes tanto a um conjunto de práticas quanto a um corpus analítico que estão, no final das contas, vinculados ao e comprometidos com o Neoliberalismo. Estabelecidos estes esclarecimentos, este trabalho prosseguiu no sentido de apontar o corpo concreto de uma bioeconomia e de um biogoverno no contexto do capitalismo contemporâneo, conferindo ênfase especial ao modo como as transformações no mundo do trabalho operam a captura de dimensões da esfera subjetiva, outrora refratárias às práticas de controle, gestão e organização do trabalho.

Sendo assim, é possível identificar uma dimensão epistemológica que está, ao mesmo tempo, articulada de forma imanente a uma dimensão sociológica e a uma dimensão econômica. Sob as especificidades da problemática que ora abordou-se, espera-se que os efeitos deste trabalho ressoem no sentido de uma percepção da existência de uma correlação, de uma relação de imanência e de um sistema de apoios e reforçamentos entre as formas de poder/governo e as formas de saber. Não é objetivo deste trabalho, entretanto, efetuar qualquer hierarquização dos males, ou extrair uma lição de moral que enuncie, sob a forma oracular da promessa "o que nós devemos fazer" - e também, muito menos, causar a impressão de que as atuais formas de dominação conseguiram minar as resistências, fechar o cerco e vedar todas as direções para impedir novas ventanias.

Será que o mundo está a tal ponto escravizado totalmente escravizado quanto o sonharam - o projetaram, o programaram e querem nos impor - nossos atuais "conselheiros pérfidos"? Postulá-los é justamente dar crédito àquilo que sai máquina quer nos fazer crer. É não ver senão a noite ou a ofuscante luz dos seus projetores. É agir como vencidos: é estar convencidos de que a máquina realizou seu trabalho sem resto e sem resistência. É não ver senão o todo. É, portanto, não ver o espaço - fosse intersticial, intermitente, nômade, improvavelmente situado - da abertura dos lampejos, dos possíveis, dos apesar de tudo. (Didi-Huberman, 2011, p. 18)

Entretanto, igualmente consiste em atitude infértil o apontamento um tanto panfletário ou um tanto aforístico dos "novos possíveis", das "formas de resistência", ou das "potencialidades de transformação" caso não se estejam cientes dos agenciamentos concretos e das formas efetivas de poder e dominação no contexto dos quais se fala e nos contextos contra os quais se fala. Não para se tornarem os pensadores sóbrios de uma revolução impossível (Deleuze \& Parnet, 2004) nem para se abandonar a percepção da ampla conectividade dos dispositivos de regulação em nome das pequenas lutas de cada dia, das pequenas vitórias cotidianas, do pequeno trabalho de formiga - o que, sob a perspectiva que aqui se adotou, bem poderia articular-se à lógica política neoliberal. É justamente para evitar essas atitudes que se julga pertinente seccionar um estrato de realidade e submetêlo à análise - o que fornece materialidade, especificidade e contextualização aos esforços aqui empreendidos. Esse extrato é justamente a bioeconomia, o biogoverno e as formas de captura da subjetividade em contextos laborais mediante as configurações do capitalismo contemporâneo.

A bioeconomia, na perspectiva defendida neste artigo, portanto, se mostra como caracterização real do desenvolvimento econômico per si. Conforme a contemporaneidade se calca, sobretudo pela sobreposição da esfera econômica à esfera política, social, ambiental, por exemplo, a bioeconomia adquire aspectos variados, partindo de uma percepção de controle mais clara à sutileza de um controle dito cognitivo, que atinge mais profunda e inteiramente o indivíduo. Não se sobrepondo ao conceito original sobre o controle da população a partir do conceito da biopolítica, a bioeconomia nos aparece enquanto desenvolvimento da própria economia política, analisada desde a escola mercantilista e revisada pela escola fisiocrática. Assim, a escola clássica adota importantes admissões do ponto de vista político e econômico: o caráter hedonista, a defesa da liberdade do mercado e a crítica ao papel do Estado interventor - admissões estas que, por sua vez, serão repassadas e por vezes criticadas pelas perspectivas posteriores. Neste contexto, considera-se de relevância a acepção do termo aos estudos sobre a contemporaneidade e ao sistema capitalista, agindo principalmente e de forma mais clara em consonância à macroestrutura neoliberal e às modalidades microfísicas de produção e captura da vida subjetiva mediante as especificidades do mundo trabalho características do século XXI.

Trata-se, em suma, de discernir as formas de dominação que são características deste tempo e apresentam-se, ao contrário, como transcendentes a este tempo - a saber, que se apresentam como consensualmente norteadoras do bem, como um progresso do qual ninguém pode ser refratário, como um avanço sem retrocessos, sem atravessamentos e sem freios. Pois, uma vez que se discerniu essas especificidades, percebe-se sua contingência e sua transitoriedade - e, então, não somente se ensaiou ou se projetou uma mudança, mas já se encontrará (em parte) no movimento que a produz.

[...] os novos dispositivos (enriquecimento das tarefas, melhoria das condições de trabalho) justificados pela intenção de romper com as formas taylorizadas do trabalho (consideradas com razão como desumanas) também ocupam posição ambígua no aspecto aqui considerado. A taylorização tradicional do trabalho consistia certamente em tratar os seres humanos como máquinas, mas não possibilitava pôr diretamente a serviço da busca do lucro 
as propriedades mais específicas dos seres humanos: afetos, senso moral, honra. Inversamente, os novos dispositivos empresariais, que exigem um engajamento mais completo e se apoiam em uma ergonomia mais sofisticada, que integra as contribuições da Psicologia pós-behaviorista e das ciências cognitivas, precisamente por serem mais humanos, também penetram mais profundamente na interioridade das pessoas esperandose que elas "se doem" ao trabalho, como se diz, e possibilitam a instrumentalização e a mercadização dos homens naquilo que eles têm de propriamente humano. (Boltanski \& Chiapello, 2009, p. 471)

\section{Referências}

Alves, G. (2011). Trabalho, Subjetividade e Capitalismo Manipulatório - o novo metabolismo social do trabalho e a precarização do homem que trabalha. Revista da RET - Rede de Estudos do Trabalho, 5(8). Recuperado em 10 de abril, 2015, de http://www.estudosdotrabalho. org/4_8\%20Artigo\%20ALVES.pdf.

Antunes, R. (1999). Os sentidos do trabalho: ensaio sobre a afirmação e a negação do trabalho. São Paulo: Boitempo.

Antunes, R. (2000). Trabalho e precarização numa ordem neoliberal. In P. Gentili, \& G. Frigotto (Orgs.), La Ciudadania Negada. Políticas de Exclusión en la Educación y el Trabajo (pp. 35-48). Buenos Aires: CLACSO. Recuperado em 22 de abril, 2015, dehttp:// biblioteca.clacso.edu.ar/ar/libros/educacion/antunes. pdf

Antunes, R. (2005). O caracol e sua concha: ensaios sobre a nova morfologia do trabalho. São Paulo: Boitempo.

Aquino, C. A. B. (2008, janeiro/junho). O processo de precarização laboral e a produção subjetiva: um olhar desde a psicologia social. O público e o privado, 6(11), 169-178. Recuperado em 25 de abril, 2015, dehttp:// seer.uece.br/?journal $=$ opublicoeoprivado\&page $=$ articl e\&op=view\&path $\% 5 \mathrm{~B} \% 5 \mathrm{D}=140 \&$ path $\% 5 \mathrm{~B} \% 5 \mathrm{D}=211$

Aquino, C. A. B., \& Martins, J. C. O. (2007). Ócio, lazer e tempo livre na sociedade do consumo e do trabalho. Revista Mal-Estar, 7(2), 479-500. Recuperado em 2 de junho, 2015, de http://hp.unifor.br/pdfs_notitia/1851. pdf

Archela, D. G. (2012). A bioeconomia como objeto de análise: perspectivas sobre o governo econômico- biológico da população. Revista UNIFAMMA, 11(1). Recuperado em 10 de junho, 2015, dehttp://revista. famma.br/unifamma/index.php/RevUNIFAMMA/ article/view/39/52

Bendassolli, P. F. (2000). Público, privado e o indivíduo no novo capitalismo. Tempo Social; Rev. Sociol. USP, 12(2), 203-236. Recuperado em 2 de abri, 2015, de http:// www.revistas.usp.br/ts/article/view/12342/14119

Boltanski, L., \& Chiapello, E. (2009). O novo espírito do capitalismo. São Paulo: Martins Fontes.

Chicchi, F. (2010, 3 de maio). Bioeconomia - Paradigma da economia contemporânea. Entrevista especial com Federico Chicchi[Entrevistaconcedida à IHU OnLine], Instituto Humanitas Unisinos. Recuperado em 29 de abril, 2015, de http://www.ihu.unisinos. br/entrevistas/32038-bioeconomia-paradigma-daeconomia-contemporanea-entrevista-especial-comfederico-chicchi

Codo, W., Sampaio, J. J. C., \& Hitomi, A. H. (1993) Individuo, trabalho e sofrimento: uma abordagem interdisciplinar. Petrópolis, RJ: Vozes.

Costa, R. (2010). Bioeconomia e Sustentabilidade da vida. Revista da FA7, 8(1), 21-34. Recuperado em 30 de abril, 2015, de http://www.fa7.edu.br/recursos/imagens/File/ Revista\%20FA7/Revista2010_1_linkcerto.pdf

Didi-Huberman, G. (2011). Sobrevivência dos vaga-lumes. Belo Horizonte: UFMG.

Dejours, C. (1999). A banalização da injustiça social. Rio de Janeiro: Fundação Getúlio Vargas.

Deleuze, G. (2010). Conversações. Rio de Janeiro: Ed. 34.

Deleuze, G., \& Parnet, C. (2004). Diálogos. Lisboa: Relógio D'Agua Editores.

Foucault, M. (2008). O Nascimento da Biopolítica. São Paulo: Martins Fontes.

Foucault, M. (2009). Segurança, Território, População. São Paulo: Martins Fontes.

Fumagalli, A. (2010a). As finanças no comando bioeconômico do trabalho vivo. Revista do Instituto Humanitas Unisinos, 10(327), 11-13. Recuperado em 30 de abril, 2015, de http://www.ihuonline.unisinos.br/ index.php?option $=$ com_content $\&$ view $=$ article $\& i d=31$ $72 \&$ secao $=327$ 
Fumagalli, A. (2010b). Bioeconomía y capitalismo cognitivo - Hacia un nuevo paradigma de acumulación. Madrid: Traficantes de Sueños.

Imbrizi, J. M. (2005). A formação do indivíduo no capitalismo tardio: uma análise de estudos que vinculam a esfera subjetiva ao mundo do trabalho. São Paulo: Fapesp.

Lazzarato, M. (2006). As revolução do capitalismo A política no Império. Rio de Janeiro: Cilização Brasileira.

Marx, K. (1980). O Capital-Crítica da Economia Política (6a. ed., livro 1, tomo 1). Rio de Janeiro: Civilização Brasileira.

Navarro, V. (1993). Produção e estado de bem-estar: O contexto político das reformas. Lua Nova: Revista de Cultura e Política, (28-29), $157-$ 200. Recuperado em 10 de maio, 2015, de http:// www.scielo.br/scielo.php?script $=$ sci_arttext\&pid $=$ S0102-64451993000100007.

Sahuquillo, M. R. (2015, 3 de abril). Trabalhadores ultra flexíveis. El País. Recuperado em 26 de maio, 2015, de http://brasil.elpais.com/brasil/2015/05/01/ internacional/1430504838_853098.html

Sennett, R. (2011). A corrosão do caráter - Consequências pessoais do trabalho no novo capitalismo (16 ${ }^{\mathrm{a}}$ ed.). Rio de Janeiro: Record.
Endereço para correspondência:

Pablo Severiano Benevides

Endereço: Rua Barão de Aracati, no 60, Meireles.

Fortaleza/CE, CEP 60115-080.

E-mail: pabloseverianobenevides@hotmail.com

\section{Endereço para correspondência:}

Tainã Alcantara de Carvalho

Endereço: Rua Germano Franck, 730, bl.06 apt.102, Parangaba. Fortaleza/CE, CEP: 60740-020.

E-mail: alcantara.ecoufc@gmail.com 